\title{
Distribution and Functions of Sterols and Sphingolipids
}

\author{
J. Thomas Hannich ${ }^{1}$, Kyohei Umebayashi ${ }^{1}$, and Howard Riezman \\ Department of Biochemistry, University of Geneva, CH-1211 Geneva 4, Switzerland \\ Correspondence: Howard.Riezman@unige.ch
}

Sterols and sphingolipids are considered mainly eukaryotic lipids even though both are present in some prokaryotes, with sphingolipids being more widespread than sterols. Both sterols and sphingolipids differ in their structural features in vertebrates, plants, and fungi. Interestingly, some invertebrates cannot synthesize sterols de novo and seem to have a reduced dependence on sterols. Sphingolipids and sterols are found in the plasma membrane, but we do not have a clear picture of their precise intracellular localization. Advances in lipidomics and subcellular fractionation should help to improve this situation. Genetic approaches have provided insights into the diversity of sterol and sphingolipid functions in eukaryotes providing evidence that these two lipid classes function together. Intermediates in sphingolipid biosynthesis and degradation are involved in signaling pathways, whereas sterol structures are converted to hormones. Both lipids have been implicated in regulating membrane trafficking.

$T^{2}$ ypical examples of eukaryotic lipids, sterols, and sphingolipids can both be found in membranes from simple unicellular fungi and protists to multicellular animals and plants. Their versatile use as structural elements but also as signaling molecules has probably played an important role during the evolution of this large and diverse group of organisms. There are also many eukaryotes that have lost the ability to synthesize sterols de novo including nematodes, insects, and marine invertebrates, which have to take up sterols with their diet. Sterol biosynthesis has also been reported in a number of

${ }^{1}$ These authors contributed equally to this article. bacteria. Sphingolipids are more widely spread among prokaryotes than sterols and also show a greater variety of structures among the different eukaryotes.

In this short review we will first give an overview about the diversity of sterol and sphingolipid structures and their distribution in nature. Then we will discuss their subcellular distribution. A brief technical section will add some information on the separation and detection of these lipid molecules. Subsequently, we will summarize different genetic approaches to study the functions of sterols and sphingolipids, and finally, we will discuss the functional and possible physical interactions of the two lipid classes within the cell. Far from being

Editor: Kai Simons

Additional Perspectives on The Biology of Lipids available at www.cshperspectives.org

Copyright (C) 2011 Cold Spring Harbor Laboratory Press; all rights reserved; doi: 10.1101/cshperspect.a004762

Cite this article as Cold Spring Harb Perspect Biol 2011;3:a004762 
J.T. Hannich et al.

comprehensive, we will focus only on a few interesting aspects and try to give new view points, which are less frequently discussed.

\section{STRUCTURES AND DISTRIBUTION AMONG SPECIES}

Sterol biosynthesis probably evolved after the emergence of oxygen about 2.5 billion years ago (Galea and Brown 2009). The first dedicated step, which is common to all sterol biosynthetic pathways, is the mono-oxygenation of squalene catalyzed by Squalene Epoxidase/ Erglp and uses molecular oxygen. Even at this early step in the pathway, the cyclization of the linear precursor, which gives rise to the polycyclic sterol ring structure, shows a diversification between kingdoms, with cycloartenol as the product in most algae and plants and lanosterol in fungi and animals (Volkman 2003). Recently, it was found that some plants also have the ability to produce lanosterol, which can contribute to phytosterol biosynthesis (Ohyama et al. 2009). Both cycloartenol synthase and lanosterol synthase are closely related to each other and to the bacterial squalene-hopene cyclases, which produce the bacterial polycyclic hopenoids without a requirement for molecular oxygen and which are most likely the evolutionary ancestors of the sterol biosynthetic enzymes. Cycloartenol and lanosterol are further metabolized via (de-) methylations and double-bond modifications to give rise to the final sterol products: several C-24 alkylated phytosterols, $\mathrm{C}_{28}$ campesterol, $\mathrm{C}_{29}$ sitosterol, and stigmasterol in plants (Benveniste 1986), a single C-24 methylated $\mathrm{C}_{28}$ ergosterol in most fungi (Weete et al. 2010), and the single nonmethylated $\mathrm{C}_{27}$ cholesterol in animals (Gaylor 2002) (Table 1). Most invertebrates including the important genetic model organisms Drosophila melanogaster and Caenorhabditis elegans have lost the ability to synthesize sterols (Clayton 1964; Kurzchalia and Ward 2003). They are

Table 1. Sterol and sphingolipid structures and distribution among species.

\begin{tabular}{|c|c|c|c|c|c|}
\hline Organism & Plants & Fungi & Vertebrates & $\begin{array}{l}\text { Auxotrophic } \\
\text { invertebrates }\end{array}$ & Bacteria \\
\hline Main sterol & \begin{tabular}{|c|} 
Campesterol $(\mathrm{R}=$ methyl) \\
Sitosterol $(\mathrm{R}=$ ethyl) \\
Stigmasterol ( $=$ ethyl, $\Delta 22)$
\end{tabular} & $\begin{array}{c}\text { Ergosterol, } \\
\text { some exceptions }\end{array}$ & Cholesterol & $\begin{array}{l}\text { Modifications of } \\
\text { dietary sterols }\end{array}$ & $\begin{array}{l}\text { Generally absent, } \\
\text { very few exceptions }\end{array}$ \\
\hline $\begin{array}{l}\text { Main sphingoid } \\
\text { base }\end{array}$ & $\begin{array}{l}\text { Several bases including: } \\
\qquad \begin{array}{l}\mathrm{d} 18: 1^{\Delta 8^{*}} \\
\mathrm{~d} 18: 2^{\Delta 4 \Delta 8^{*}} \\
\mathrm{t} 18: 1^{\Delta 8^{*}}\end{array}\end{array}$ & $\begin{array}{c}\text { Variety of structures } \\
\text { S. cerevisiae: } \\
\text { sphinganine }\left(\mathrm{d} 18: 0^{*}\right) \\
\text { phytosphingosine (t18:0*) } \\
\text { P. pastoris: 9-methyl- } \\
\text { sphinga-4,8,-dienine }\end{array}$ & $\begin{array}{c}\text { Sphingosine } \\
\left(\mathrm{d} 18: 1^{\Delta 4^{*}}\right) \\
\text { several others present }\end{array}$ & $\begin{array}{c}\text { D. melanogaster: } \\
\mathrm{C}_{14} \text { sphingosine } \\
\text { C. elegans: } \\
\mathrm{C}_{17} \text { iso-sphingosine }\end{array}$ & $\begin{array}{l}\text { Mostly absent, } \\
\text { some exceptions }\end{array}$ \\
\hline $\begin{array}{c}\text { Higher } \\
\text { sphingolipids }\end{array}$ & \begin{tabular}{|c|}
-Inositolphosphoryl \\
glycolipids \\
-Glycosphingolipids \\
(mainly glucosyl-, some \\
mannosylceramide series)
\end{tabular} & $\begin{array}{l}\text {-Inositolphosphoryl } \\
\text { glycolipids } \\
\text {-Glycosphingolipids } \\
\text { S. cerevisiae: only } \\
\mathrm{IPC}^{+}, \mathrm{MIPC}^{+}, \mathrm{M}(\mathrm{IP})_{2} \mathrm{C}^{+}\end{array}$ & $\begin{array}{c}\text {-Sphingomyelin } \\
\text {-Glycosphingolipids } \\
\text { (mainly glucosyl-, some } \\
\text { galactosylceramide series) }\end{array}$ & $\begin{array}{l}\text {-Sphingomyelin (C. elegans) } \\
\text {-Phosphoethanolamine } \\
\text { ceramide (D. melanogaster) } \\
\text {-Glucosyl ceramide series }\end{array}$ & $\begin{array}{c}\text { Mostly absent, } \\
\text { some exceptions with } \\
\text { glucosyl ceramide } \\
\text { series }\end{array}$ \\
\hline SREBP & Not found & $\begin{array}{l}\text { Oxygen sensor, } \\
\text { but not found in } \\
\text { S. cerevisiae }\end{array}$ & $\begin{array}{l}\text { SREBP1a/c regulate fatty } \\
\text { acid \& fat metabolism } \\
\text { SREBP2 regulates sterol } \\
\text { metabolism }\end{array}$ & $\begin{array}{l}\text { Regulates fatty acid and } \\
\text { fat metabolism }\end{array}$ & Not found \\
\hline
\end{tabular}

*Shorthand nomenclature for sphingoid bases "aXX:Y $\Delta Z$ ": a-number of hydroxylgroups $(d=2, t=3)$; XX-number of carbon atoms; Y-double bonds, $\Delta \mathrm{Z}$-position of double bonds.

${ }^{+}$IPC-inositolphosphorylceramide, MIPC-mannosylinositolphosphorylceramide, $\mathrm{M}(\mathrm{IP})_{2} \mathrm{C}$-mannosyldiinositolphosphorylceramide. 
dependent on external sterol sources and use some of the remaining conserved sterol biosynthetic enzymes for sterol modifications, including steroid hormone production (Vinci et al. 2008) and regulation (Hannich et al. 2009).

Another very important feature of sterol biosynthesis in vertebrates is its regulation by the membrane bound basic helix-loop-helix (bHLH) transcription factor SREBP (Osborne and Espenshade 2009). The vertebrate genome contains two copies encoding three isoforms with SREBP-2 regulating mainly cholesterol biosynthesis and SREBP-1a and c regulating mainly fatty acid and phospholipid metabolism as well as fat storage. Invertebrates have one copy of SREBP, which has been shown to regulate fatty acid and phospholipid metabolism in flies and fatty acid metabolism and fat accumulation in worms (see Ye and Debose-Boyd 2011). Although no SREBP homolog has yet been found in Saccharomyces cerevisiae, other fungi like Schizosaccharomyces pombe also express a copy that serves as a sterol-dependent oxygen sensor that regulates oxygen-dependent steps in ergosterol, heme, and sphingolipid metabolism (Todd et al. 2006). So far no SREBP homolog has been described in plants even though a number of membrane-bound bHLH transcription factors still await further characterization.

A detailed description of sphingolipid biosynthesis can be found in recent reviews (Hannun and Obeid 2008; Futerman and Riezman 2005). Sphingolipids are a very diverse class of lipids, which is predicted to include tens of thousands or maybe more distinct structures (Merrill et al. 2009). This diversity is due to combinations of structural varieties of sphingoid bases, the $\mathrm{N}$-acylated fatty acid, and the polar head group. The basic structure of the central building block, the sphingoid/longchain base (LCB), depends on the substrate specificity of its biosynthetic enzymes.

The main vertebrate LCB is D-erythrosphingosine (short d18:1 $\Delta 4 E$ for $(2 S, 3 R, 4 E)$ 2-aminooctadec-4-ene-1,3-diol; see Table 1 legend for an explanation of the shorthand nomenclature) but in addition also substantial amounts of $\mathrm{C}_{20}$ and minor amounts of $\mathrm{C}_{12}$ to
$\mathrm{C}_{22}$ (Han and Jiang 2009) as well as 1-deoxy and 1-deoxymethyl long chain bases can be found (Penno et al. 2010). Differences in double bonds and base hydroxylation additionally give rise to sphinganine (d18:0), phytosphinganine (t18:0), and their analogues. Also in plants $\mathrm{C}_{18}$ sphingoid bases, especially with $\Delta 8$ and $\Delta 4 \Delta 8$ double bonds, predominate (Pata et al. 2010). Many fungi additionally methylate the alkyl chain at C-9, giving rise to $\mathrm{C}_{19}$ bases (Ternes et al. 2006), but the baker's yeast $S$. cerevisiae produces only sphinganine and phytosphinganine (mainly $\mathrm{d} 18: 0$ and $\mathrm{t} 18: 0$, some $\mathrm{d} 20: 0$, and t20:0). In invertebrates other chain lengths are abundant. Flies produce mainly $\mathrm{C}_{14}$ and some $\mathrm{C}_{16}$ straight chain bases (Acharya and Acharya 2005), whereas nematodes build their sphingolipids from $\mathrm{C}_{17}$ iso-branched sphingoid bases (Chitwood et al. 1995). Free LCBs exist only at very low levels in the cell. Most of these can be phosphorylated to form sphingosine-1-phosphate and other phosphorylated sphingoid bases. The majority of sphinganine is transformed into dihydroceramide (likewise for other sphingoid bases) by $\mathrm{N}$-acylation with fatty acids ranging from $\mathrm{C}_{14}$ to $\mathrm{C}_{26}$ or perhaps even up to $\mathrm{C}_{36}$ in rare cases. The majority of incorporated fatty acids are saturated or monounsaturated and can be modified with an $\alpha$ and one additional hydroxylation. Great diversity between species is created by different polar head groups that are attached to the C-1 hydroxyl group of the ceramide backbone to create higher sphingolipids, including phosphosphingolipids, glycosylinositolphosphorylceramides, and glycosphingolipids. Phosphorylation leads to ceramide-phosphate but also the phosphobases phosphocholine and phosphoethanolamine can be attached. These give rise to sphingomyelin, which is abundant in vertebrates and some invertebrates like C. elegans, and phosphoethanolamine ceramide, which is only produced in very low amounts in mammalian cells (Vacaru et al. 2009) but replaces sphingomyelin in D. melanogaster (Acharya and Acharya 2005). Plants and fungi have a series of glycolipids that are derived from inositolphosphoryl ceramide (IPC), which can have a diverse range of more or less complex (modified) sugar chains 
J.T. Hannich et al.

attached to it (Pata et al. 2010). Plants, fungi, invertebrates, and vertebrates all also transfer sugars directly onto the ceramide moiety to form glycosphingolipids. In plants, glucosylceramide predominates and serves as a basic structure for series of up to tetraglycosylceramides but also some mannosylceramide series are produced (Sperling and Heinz 2003). Glucosyl- and to a lesser degree galactosylceramides are also widely spread among fungi, even though $S$. cerevisiae does not show any glycosylceramides. In invertebrates and vertebrates, hundreds of different head group structures are formed by adding different chains of sugar molecules and their derivatives to the first sugar moiety, which is mainly glucose. In addition, vertebrates also show a series of galactosylceramide-based glycolipids. In $S$. cerevisiae the higher sphingolipids are inositolphosphoryl ceramide (IPC), and its derivatives mannosyl inositolphosphoryl ceramide (MIPC), and mannosyl di-inositolphosphoryl ceramide $\left(\mathrm{M}(\mathrm{IP})_{2} \mathrm{C}\right)$ (Dickson and Lester 1999).

Very few studies have shown unequivocally the presence of sterols in prokaryotes, but both biochemical and genomic analysis have identified a fairly elaborated sterol biosynthetic pathway in Methylococcus capsulatus producing also demethylated sterols (Bird et al. 1971; Lamb et al. 2007) and a very basic pathway in Gemmata obscuriglobus that only produces cycloartenol and its isomer parkeol (Pearson et al. 2003). Most likely the last eukaryotic common ancestor (LECA) produced an elaborate set of sterols via the cycloartenol pathway and differences with modern day eukaryotes are characterized by small changes, including side chain methylations (Desmond and Gribaldo 2009). Although these rare observations of bacterial sterol biosynthesis were initially explained by horizontal gene transfer from an early eukaryote, the dynamic endo-membrane system of G. obscuriglobus and the recent discovery of its membrane coat-like proteins, both additional key eukaryotic features, have tempted others to suggest a close relationship of these bacteria to the origin of eukaryogenesis (Santarella-Mellwig et al. 2010). To date no side-chain C-24 alkylation has been observed in prokaryotes and this metabolic feature is therefore used as a signature for different eukaryotic traces in paleogeology (Summons et al. 1988).

Production of sphingolipids in bacteria is more widespread. The first crystal structure for a sphingolipid biosynthetic enzyme was obtained from a soluble bacterial serine palmitoyl transferase (SPT) (Yard et al. 2007). Recently, the sphingosine 1 phosphate lyase structure was determined from Symbiobacterium thermophilum (Bourquin et al. 2010). In some species like Sphingomonas capsulata, glycosphingolipids functionally replace lipopolysaccharide in the outer membrane (Geiger et al. 2010). It can be assumed that sphingolipid biosynthesis first evolved in prokaryotes from other members of the $\alpha$-oxoamine synthase family, which fuse organic acids to amino acids, and probably was already present in the LECA. So far, no prokaryotes with both sphingolipid and sterol synthesis have been discovered to our knowledge.

\section{DISTRIBUTION WITHIN CELLS}

It is a long-standing dogma that concentrations of sterols increase along the secretory pathway, being very low in the ER, higher in the Golgi, and highest in the plasma membrane. Sterols have also been shown to be enriched in early and recycling endosomes, but not late endosomes. In lipid storage diseases such as Niemann-Pick type C (NPC), sterol and sphingolipids are abnormally accumulated in late endocytic compartments (Mesmin and Maxfield 2009). In our opinion this dogma still needs to be confirmed by unequivocal experimental data. Many studies on sterol localization depend on binding to filipin, but we do not have sufficient molecular insights into how filipin binds cholesterol and other sterols as the structure of the complex has not been determined. There is also substantial experimental data suggesting that the evaluation of sterol concentration by filipin binding is dependent on membrane composition (see Jin et al. 2008, as an example). The sterol content of a specific organelle can also be measured by subcellular fractionation and lipid quantification, however many 
of the previous studies, while using state of the art purification techniques, did not analyze pure fractions. As will be discussed later, current advances in mass spectrometry and organelle immunopurification should provide comprehensive information about the lipid composition of isolated organelles, thereby allowing us to address the reality of the dogma. Recently, highly purified ER membrane was prepared, and subsequent quantification by mass spectrometry showed a very delicate threshold of sterol regulatory element-binding protein (SREBP)-mediated cholesterol sensing (Radhakrishnan et al. 2008): the ER cholesterol concentration above or below $5 \mathrm{~mol} \%$ is sharply distinguished. In addition, a quantitative shotgun lipidomics approach (Ejsing et al. 2009) showed that post-Golgi secretory vesicles are enriched in sterols and sphingolipids, consistent with the idea that lipid sorting occurs in the trans-Golgi network (Klemm et al. 2009). In this study, the vesicles were purified from a conditional yeast mutant. It is highly difficult to isolate organelles without contamination, for example separation of Golgi and endosomes is generally difficult and even immunoisolation techniques will have to rely on proteins other than the many that cycle between the two compartments. Due to the high sensitivity of mass spectrometry it is no longer necessary to isolate large amounts of purified organelles for analysis and therefore, more sophisticated and selective techniques can now be used. It is important to develop such techniques in order to gain insight into normal and abnormal states, such as normal and NPC endosomes.

In model membranes, under optimal conditions of lipid composition and temperature, sterols and sphingolipids are laterally segregated from other lipids to form different physical phases, including a liquid-ordered phase. The concept of "lipid raft" states that these phase separations also occur in biological membranes, incorporating specific proteins that preferentially interact with these two lipids. Currently, lipid rafts are considered to be highly dynamic nanoscale structures (Lingwood and Simons 2010).

As mentioned above, sterols have been localized by making use of sterol-binding compounds, including fluorescent filipin, which has long been used for this purpose. In both yeast and mammalian cells, filipin stains the plasma membrane and intracellular compartments, probably the endosomes and perhaps the Golgi. Using filipin, genome-wide screening for genes regulating sterol localization was conducted in both yeast and mammalian cells. These studies identified many genes, suggesting the complexity of intracellular sterol localization. For example, in yeast mutants deleted for phospholipase $\mathrm{C}$ (PLC1) or protein phosphatase type 2C (PTC1) gene, intense filipin staining was observed in intracellular compartments, probably late endosomes (Fei et al. 2008). Thus, signal transduction pathways involving these proteins may sense and/or control sterol homeostasis. The screening of mammalian cells identified a novel endolysosomal protein TMEM97 whose knockdown reduced the intensity of filipin staining as well as uptake of fluorescent LDL, and this protein was coimmunoprecipitated with NPC1 (Bartz et al. 2009). Independent of such screening, abnormal filipin staining was observed in yeast mutants defective in GPI biosynthesis (Schonbachler et al. 1995; Kajiwara et al. 2008). Some gpi mutants are also defective in sphingolipid biosynthesis, possibly affecting the step of ceramide transport, suggesting that GPI-anchored proteins may facilitate sterol and sphingolipid transport to the cell surface. The existence of the GPI moiety, whose structure is remodeled from a diacylglycerol to ceramide in yeast may stabilize or participate in sterol-sphingolipid interactions affecting transport.

Ergosterol biosynthesis is a common target of antifungal drugs, such as polyene antibiotics amphotericin $\mathrm{B}$, natamycin, and nystatin. Recently, a natural antifungal compound theonellamide (TNM) was shown to target $3 \beta$ hydroxysterol (Ho et al. 2009; Nishimura et al. 2010). TNM is an unusual bicyclic peptide and represents a novel class of sterol-binding compounds. As described below, yeast cells can be stained using a fluorescent version of TNM.

The initial steps of sphingolipid biosynthesis, including sphingoid base and ceramide formation, take place in the endoplasmic reticulum 
J.T. Hannich et al.

(Futerman and Riezman 2005). Higher sphingolipids are produced in the Golgi apparatus where they are transported by different mechanisms. In mammalian cells, ceramides for glycosphingolipid production seem to be transported via a different pathway than SM, which is produced from a specific ceramide pool transported via a nonvesicular pathway mediated by the CERT protein (Hanada et al. 2003). In yeast cells both vesicular and nonvesicular ER to Golgi ceramide transport exists (Funato and Riezman 2001). Most higher sphingolipids are transported to the plasma membrane.

\section{METHODS OF SEPARATION AND DETECTION}

Mass spectrometric shotgun lipidomics as described by Schwudke et al. (2011) is a powerful analytical technique with many advantages but also limitations with respect to sterol and sphingolipid analysis even though careful sample preparation and high dilutions can reduce ion suppression by glycerophospholipids in the nonseparated extract. Utilization of a chipbased nano-spray setup provides high reproducibility, whereas removal of phosphoglycerolipids and triacylglycerides by base treatment makes it possible to detect a variety of sphingolipids (Jiang et al. 2007), although there are isomeric species that cannot be distinguished (like glucosyl and galactosyl ceramides) and many overlapping isotopic species that could be resolved by high mass accuracy fourrier transformation mass spectrometry often show signals that are too weak to gain structural information based on fragmentation. Different protocols based on high performance liquid chromatography coupled to ESI-MS have been tailored for specific lipid classes (Sullards et al. 2007). Although column separation increases sensitivity and structural information it also introduces problems to the analysis, including changing ionization conditions during the course of the analysis and column memory. For quantitative analysis it is important to ensure that internal standards elute under the same ionization conditions as the respective analytes, which is easier on normal-phase columns in which lipids elute as lipid classes. Absolute quantification would require a standard curve for every analyzed molecule at the respective ionization condition or a corresponding stable isotope labeled standard for each molecule. Although both possibilities are not realistic in a vertebrate system the second one is actually feasible for the rather simple sphingolipidome of $S$. cerevisiae (Ejsing et al. 2009). In most systems a sufficient number of internal standards containing unnatural and stable isotope labeled lipids can ensure semiquantitative lipid analysis.

In addition, the precise identification of most sterols cannot be determined based solely on mass measurements. Different chromatographic methods have been developed to increase sensitivity by removing ion-suppressing background and to differentiate molecular structures based not only on mass and fragmentation but also on retention time, which is determined by structural differences even between isomeric species. In the case of sterols, gas chromatography coupled to an EI-source has proven to give reliable results (Guan et al. 2009).

\section{GENETIC APPROACHES TO STEROL AND SPHINGOLIPID FUNCTION}

Both sterols and sphingolipids play important structural roles in many cellular membranes. Sterols have been shown to influence fluidity and permeability of membranes, both in vitro and in vivo (Haines 2001; Emter et al. 2002). Still, at least some eukaryotic cells, like cultured insect cells, can function without almost any sterol in their membranes (Silberkang et al. 1983) and it has been proposed that sphingolipids with dien-sphingoid bases can replace sterols in the membrane (Carvalho et al. 2010). Certain glycosphingolipids have also been proposed to serve a structural role, for example in the chilling response of plants (Pata et al. 2010). Another very important role of sterols that has to be kept in mind when studying their cellular functions is the production of different signaling molecules. Multicellular organisms rely on sterol-derived hormones like the steroids of vertebrates, brassinosteroids of plants and 
ecdysteroids, or other molting hormones of invertebrates. Other sterol-derived signaling molecules include Vitamin D, bile acids, and oxysterols (Kurzchalia and Ward 2003).

Yeast genetics has been a powerful tool to elucidate the biosynthesis and functions of sterols and sphingolipids. Mutants defective in various steps of these metabolic pathways were isolated. Many efforts have focused on mutants ( $\operatorname{erg} 2, \operatorname{erg} 3, \operatorname{erg} 4, \operatorname{erg} 5$, and $\operatorname{erg} 6)$ defective in the last five steps of the biosynthesis, because each is a nonessential step. In these mutants, ergosterol is absent and specific sterol intermediates are accumulated. The erg mutants are defective in many cellular processes, indicating that ergosterol cannot be replaced by the sterol intermediates. The differences between ergosterol and the intermediates are the desaturation status of the A and B rings and the side chain modifications. Despite the slight differences from one another, each erg mutant has distinct defects. For example, endocytic internalization from the plasma membrane is strongly affected in the erg2 mutant, defective in the C-8 sterol isomerase activity, but not drastically altered in the erg6 mutant, defective in the C-24 sterol methyltransferase activity (Munn et al. 1999; Heese-Peck et al. 2002). This highlights the structural importance of sterol. Because yeast cells do not take up sterol from the medium under aerobic conditions, the sterol composition of each mutant is clearly defined and can be quantitatively determined by GC-MS. Notably, changes in ergosterol structure in the different erg mutants confer different sphingolipid compositions, without affecting glycerophospholipids, as determined by mass spectrometry (Guan et al. 2009). Thus, cells adjust their sphingolipid profile in response to changes in sterol structures, strongly suggesting that sterols and sphingolipids interact, perhaps physically. Using combinations of mutations in sterol and sphingolipid biosynthesis a number of synthetic and suppression phenotypes were found. These findings led to the conclusion that sterols and sphingolipids interact functionally in biological membranes.

It is theoretically possible that changes in membrane fluidity could account for many of the defects in erg mutants. However, results measuring plasma membrane fluidity by fluorescence anisotropy of TMA-DPH did not correlate with the severity of the mutant phenotypes (Guan et al. 2009). It was postulated that defective protein-lipid interactions in the erg mutants caused the defects. One hypothesis is that some membrane proteins cannot fit into the altered membranes and their folding or activities are impaired. One of the noticeable phenotypes of the erg6 mutant is reduced uptake of tryptophan from the medium (Gaber et al. 1989). This is because the high-affinity tryptophan permease Tat2 is inappropriately ubiquitinated and missorted to the vacuole (Fig. 1) (Umebayashi and Nakano 2003). The missorting of Tat2 is common to other erg mutants (Daicho et al. 2009; Guan et al. 2009), indicating that the sorting of Tat2 is very sensitive to sterol structures, strictly requiring ergosterol. One possibility is that Tat 2 interacts with sterol-sphingolipid complexes and, in the erg mutants, Tat 2 is misfolded and placed under ubiquitin surveillance. Identification of other membrane proteins that undergo ubiquitination in the erg mutants would help us to explain their diverse phenotypes. Alternatively, the erg mutants may have a defect in signaling, such as amino acid sensing, so that they always sort Tat 2 to the vacuole. There have been two examples of signaling involved in Tat 2 sorting. First, plasma membrane localization of Tat 2 is regulated by the nutrient availability, which is sensed by the target of rapamycin (TOR) kinase (Fig. 1). Following starvation, TOR is inactivated and Tat 2 is sorted to the vacuole in a ubiquitin-dependent manner (Beck et al. 1999). Downstream from TOR, the Nprl kinase and the type 2A phosphatase-associated protein Tap42 are involved in this regulation (Schmidt et al. 1998). Second, addition of the exogeneous LCB phytosphingosine (PHS) inhibits tryptophan uptake, most likely by transducing a signal that down-regulates Tat2 (Fig. 1) (Skrzypek et al. 1998). In addition to being substrates of ceramide synthases, LCBs are known as signaling molecules that activate yeast PDK1 kinase homologs Pkh1 and Pkh2 as well as AGC kinase homologs Ypk1 and Ypk2 (Sun 
J.T. Hannich et al.
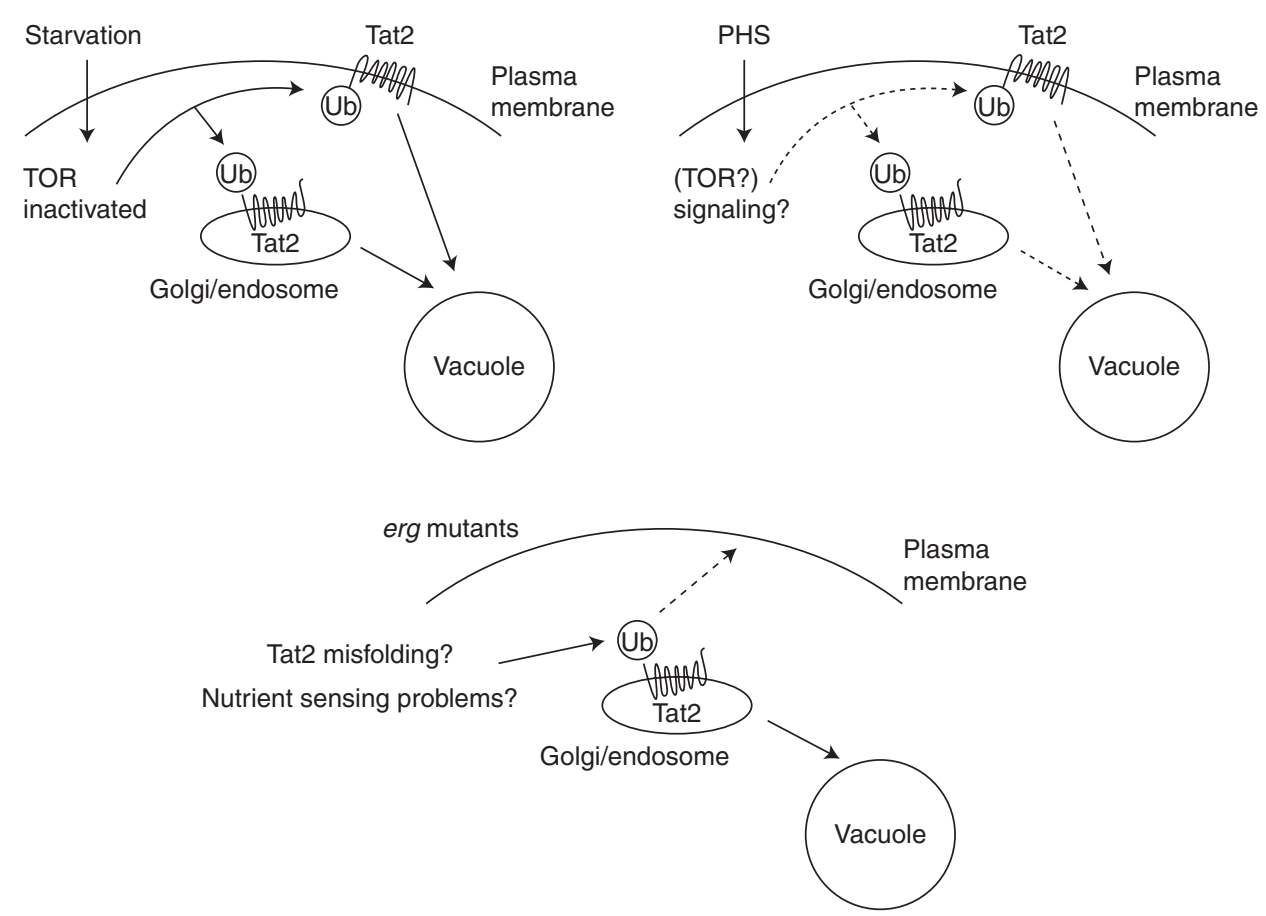

Figure 1. Regulation of Tat2 sorting to the vacuole. (Upper left) Following starvation, the TOR signaling pathway is inactivated. This leads to ubiquitin-dependent sorting of both newly synthesized and plasma membranelocalized Tat2 to the vacuole. (Upper right) Exogeneous PHS down-regulates Tat2, possibly by ubiquitination and vacuolar sorting. Signals activated by PHS remain to be elucidated. (Lower) In erg mutants, Tat2 is inappropriately ubiquitinated and sorted to the vacuole, not the plasma membrane. One possible reason is that Tat 2 is misfolded by the altered sterol and sphingolipid composition. Alternatively, the sterol mutants may be defective in nutrient sensing.

et al. 2000; Friant et al. 2001; Liu et al. 2005). Although the putative signaling pathway between the exogeneous PHS and Tat2 downregulation has not been characterized yet, this may be linked to the TOR pathway. Aronova et al. (2008) showed that TOR complex 2 (TORC2) regulates ceramide synthesis by activating the Ypk2 kinase. Considering that Tat2 localization is influenced by TOR signaling, it is interesting that sterols and sphingolipids have recently been implicated in regulation of TORC1 and TORC2. In yeast, it was shown that TORC2 activity is synthetically impaired in a sterol and sphingolipid double mutant (Guan et al. 2009). In mammalian cells, cholesterol trafficking defects such as NPC deficiency reduce the activities of the two TORCs (Xu et al. 2010). Since TORC1 couples amino acid availability to cell growth, sterols and sphingolipids may influence amino acid sensing through TORC1. Notably, TORC1 is associated with the vacuole/lysosome membrane (Sturgill et al. 2008; Sancak et al. 2010). Its activity and/ or localization could be sensitive to the lipid content of this organelle.

Lipid rafts have also been proposed to act as signaling platforms, clustering signaling molecules for efficient transmission. During mating, haploid yeast cells are polarized into pearshaped "shmoos", and MAPK signaling is activated to direct signaling required for mating. At the shmoo tip, both filipin staining and the MAPK scaffold protein Ste5 are concentrated (Pryciak and Huntress 1998; Bagnat and Simons 2002). One of the common phenotypes among the erg2-6 mutants is reduced mating efficiency, including the MAPK signaling and subsequent plasma membrane fusion. 
Strikingly, the erg3 mutant is defective in the polarized plasma membrane localization of Ste5 (Jin et al. 2008). Thus, correct sterol composition is required for the polarized recruitment of a signaling molecule. Ste5p binds to $\mathrm{PI}(4,5) \mathrm{P}_{2}$ through its $\mathrm{PH}$ domain, and this is important for its correct localization (Garrenton et al. 2006). It seems that $\mathrm{PI}(4,5) \mathrm{P}_{2}$ is concentrated at the shmoo tip in wild-type cells, but not in the erg6 mutant (Jin et al. 2008). Further work is needed to understand how sterol influences the $\mathrm{PI}(4,5) \mathrm{P}_{2}$ distribution.

Although ergosterol is enriched in the plasma membrane, the localization of sterol intermediates seems to be somewhat different. When fission yeast cells are stained with the fluorescent TNM, the cell periphery is clearly labeled in wild-type but the labeling is very weak in the erg2 or erg3 mutant (Nishimura et al. 2010). The binding of TNM to the sterol fractions prepared from these mutants was normal, strongly suggesting that the sterol intermediates are not preferentially localized to the plasma membrane. Consistent with this, the erg3 mutant of the budding yeast shows abnormal filipin staining with significant labeling of cytoplasmic spots (Fei et al. 2008). The reason for the altered localization is unclear, but the structural changes in sterol-sphingolipid complexes may facilitate clearance from the plasma membrane or provide limited access to sterol transport proteins. In any case, reduced sterol levels in the plasma membrane could affect the sorting and function of plasma membrane proteins such as Tat2.

The above results clearly indicate that subtle differences in sterol structure drastically affect various membrane-related cellular events in yeast. Also in mammals, it has been reported that defects in late cholesterol biosynthetic steps cause severe diseases. Mutations in a $\Delta^{8}-\Delta^{7}$ sterol isomerase were identified in human X-linked dominant chondrodysplasia punctata as well as its relevant disease in mice (Derry et al. 1999). This enzyme isomerizes a double bond in the $\mathrm{B}$ ring, the same reaction as catalyzed by yeast Erg2p. Indeed, both the murine and human enzymes complement the yeast erg2 mutant to produce ergosterol (Silve et al.
1996). Although the C7-C8 double bond introduced by $\operatorname{Erg} 2 / \Delta^{8}-\Delta^{7}$ sterol isomerase persists in ergosterol, it is removed by 7-dehydrocholesterol reductase (DHCR7) to form cholesterol. Mutations in the DHCR gene cause Smith-Lemli-Opitz syndrome with developmental abnormalities (Fitzky et al. 1999). Thus, unlike yeast, the C7-C8 double bond has to be removed in mammals. These diseases tell us that correct sterol biosynthesis is vital also in mammals. It is not clear whether the phenotypes seen in yeast and human mutants are due to the lack of cholesterol or the presence of sterol intermediates. If the former is the case the defects might be alleviated by feeding cholesterol. If the latter, this strategy would not work. As mentioned above, the yeast erg mutants are defective in mating. When the erg4 mutant was forced to take up ergosterol under an anaerobic condition, it restored shmoo formation but not subsequent cell fusion (Aguilar et al. 2010). However, under these conditions, de novo ergosterol synthesis is shut down because of lack of oxygen and the only source of ergosterol is that taken up from the medium.

Sphingolipids, especially LCBs, ceramides and their phosphorylated forms are important signaling molecules (Fyrst and Saba 2010) whose numerous functions in vertebrates will not be described in detail here. Sphingosine 1 phosphate is an extracellular signaling molecule that binds to G-protein coupled receptors and controls cell migration and many other physiological parameters. Recently, intracellular functions of sphingosine 1 phosphate in vertebrates have been revealed in control of protein ubiquitination (Alvarez et al. 2010) and transcription (Hait et al. 2009). In yeast, recent studies integrating genomic, transcriptomic, and lipidomic data have revealed a role for phytosphinganine 1 phosphate in regulating genes involved in mitochondrial respiration (Cowart et al. 2010). Another sphingolipid connection to mitochondrial function comes from the dual localization of the yeast sphingomyelinase homolog, Isclp, which is found in both ER and mitochondria (Vaena de Avalos et al. 2004).

Genetic approaches have allowed the identification of most of the enzymes in sphingolipid 
J.T. Hannich et al.

metabolism in yeast (Dunn et al. 2000; Dickson et al. 2006) and many homologs have been found in other systems (Futerman and Riezman 2005). Sphingolipids play a large number of roles in yeast, many of which have been recently reviewed (Dickson 2008). A number of roles for LCBs in yeast have been identified by use of a temperature-sensitive mutant in serine palmitoyltransferase (lcb1-100) activity, which was originally isolated as an endocytosis mutant (end8) (Munn and Riezman 1994). LCBs were shown to activate the Pkh1 and 2 kinases to regulate the actin cytoskeleton and the internalization step of endocytosis (Friant et al. 2000, 2001; Zanolari et al. 2000). Interestingly, sphingolipid metabolism also affects the endocytic pathway in D. melanogaster, genetically interacting with components of the internalization machinery, such as dynamin (Rao and Acharya 2008). The lcb1-100 also shows defects in membrane protein maturation and trafficking, including the plasma membrane ATPase (Lee et al. 2002; Gaigg et al. 2005, 2006) and GPI-anchored proteins (Horvath et al. 1994; Bagnat et al. 2000; Watanabe et al. 2002). In both cases, the evidence suggests that the synthesis of ceramides is important. For the GPI-anchored proteins this could be because of the fact that most GPI-anchored proteins are remodeled to contain ceramide (Reggiori et al. 1997) and that this step is required for their concentration into ER exit sites (Castillon et al. 2009). Sphingolipids also play roles in regulation of translation affecting formation of RNA processing bodies (Cowart et al. 2010) and regulating translation initiation during the heat shock response (Meier et al. 2006).

S. cerevisiae mutants with a defect in synthesis of MIPC show a hypersensitivity to calcium ions (Beeler et al. 1997), but MIPC synthesis does not seem to be required for targeting of plasma membrane proteins (Lisman et al. 2004). However, in S. pombe MIPC does seem to play a role in plasma membrane protein localization (Nakase et al. 2010).

In mammalian systems a large variety of functions have been ascribed to sphingolipids and functional insights have also been derived from genetic approaches, including the identification of CERT (Hanada et al. 2003) and insights derived from the analysis of knockout mice, including mutants in glycosylceramide synthase (Yamashita et al. 1999; Sprong et al. 2001) and ceramide synthase 2 (Imgrund et al. 2009; Pewzner-Jung et al. 2010a,b). Mutants in ceramide synthases in D. melanogaster (Bauer et al. 2009) and C. elegans (Deng et al. 2008) have also provided new functions for sphingolipids in these organisms, including regulation of the response to anoxia (Menuz et al. 2009), while mutants in other steps of sphingolipid synthesis have been linked to gut development (Marza et al. 2009). We are still early in the period of the use of genetics to study sphingolipid and sterol function in animals and together with the new tools of lipidomics we can expect an exciting period in the years to come.

\section{ACKNOWLEDGMENTS}

The work of the authors was supported by grants from the Swiss National Science Foundation (HR), SystemsX.ch (evaluated by the SNSF), the European Science Foundation (EuroMembrane), and an EMBO long-term fellowship (J.T.H).

\section{REFERENCES}

Acharya U, Acharya JK. 2005. Enzymes of sphingolipid metabolism in Drosophila melanogaster. Cell Mol Life Sci 62: $128-142$.

Aguilar PS, Heiman MG, Walther TC, Engel A, Schwudke D, Gushwa N, Kurzchalia T, Walter P. 2010. Structure of sterol aliphatic chains affects yeast cell shape and cell fusion during mating. Proc Natl Acad Sci 107: 41704175.

Alvarez SE, Harikumar KB, Hait NC, Allegood J, Strub GM, Kim EY, Maceyka M, Jiang H, Luo C, Kordula T, et al. 2010. Sphingosine-1-phosphate is a missing cofactor for the E3 ubiquitin ligase TRAF2. Nature 465: 10841088.

Aronova S, Wedaman K, Aronov PA, Fontes K, Ramos K, Hammock BD, Powers T. 2008. Regulation of ceramide biosynthesis by TOR complex 2. Cell Metab 7: 148-158.

Bagnat M, Simons K. 2002. Cell surface polarization during yeast mating. Proc Natl Acad Sci 99: 14183-14188.

Bagnat M, Keranen S, Shevchenko A, Simons K. 2000. Lipid rafts function in biosynthetic delivery of proteins to the cell surface in yeast. Proc Natl Acad Sci 97: $3254-3259$. 
Bartz F, Kern L, Erz D, Zhu M, Gilbert D, Meinhof T, Wirkner U, Erfle H, Muckenthaler M, Pepperkok R, et al. 2009. Identification of cholesterol-regulating genes by targeted RNAi screening. Cell Metab 10: 63-75.

Bauer R, Voelzmann A, Breiden B, Schepers U, Farwanah H, Hahn I, Eckardt F, Sandhoff K, Hoch M. 2009. Schlank, a member of the ceramide synthase family controls growth and body fat in Drosophila. EMBO J 28: 3706-3716.

Beck T, Schmidt A, Hall MN. 1999. Starvation induces vacuolar targeting and degradation of the tryptophan permease in yeast. J Cell Biol 146: 1227-1238.

Beeler TJ, Fu D, Rivera J, Monaghan E, Gable K, Dunn TM. 1997. SUR1 (CSG1/BCL21), a gene necessary for growth of Saccharomyces cerevisiae in the presence of high $\mathrm{Ca}^{2+}$ concentrations at 37 degrees $\mathrm{C}$, is required for mannosylation of inositolphosphorylceramide. Mol Gen Genet 255: 570-579.

Benveniste P. 1986. Sterol Biosynthesis. Ann Rev Plant Physiol Plant Mol Biol 37: 275-308.

Bird CW, Lynch JM, Pirt FJ, Reid WW. 1971. Steroids and squalene in Methylococcus capsulatus grown on methane. Nature 230: 473-474.

Bourquin F, Riezman H, Capitani G, Grutter MG. 2010. Structure and function of sphingosine-1-phosphate lyase, a key enzyme of sphingolipid metabolism. Structure 18: $1054-1065$.

Carvalho M, Schwudke D, Sampaio JL, Palm W, Riezman I, Dey G, Gupta GD, Mayor S, Riezman H, Shevchenko A, et al. 2010. Survival strategies of a sterol auxotroph. Development 137: 3675-3685.

Castillon GA, Watanabe R, Taylor M, Schwabe TM, Riezman H. 2009. Concentration of GPI-anchored proteins upon ER exit in yeast. Traffic 10: $186-200$.

Chitwood DJ, Lusby WR, Thompson MJ, Kochansky JP, Howarth OW. 1995. The glycosylceramides of the nematode Caenorhabditis elegans contain an unusual, branched-chain sphingoid base. Lipids 30: 567-573.

Clayton RB. 1964. The utilization of sterols by insects. J Lipid Res 15: 3-19.

Cowart LA, Shotwell M, Worley ML, Richards AJ, Montefusco DJ, Hannun YA, Lu X. 2010. Revealing a signaling role of phytosphingosine-1-phosphate in yeast. Mol Syst Biol 6: 349 .

Daicho K, Makino N, Hiraki T, Ueno M, Uritani M, Abe F, Ushimaru T. 2009. Sorting defects of the tryptophan permease Tat2 an erg2 yeast mutant. FEMS Microbiol Lett 298: 218-227.

Deng X, Yin X, Allan R, Lu DD, Maurer CW, HaimovitzFriedman A, Fuks Z, Shaham S, Kolesnick R. 2008 Ceramide biogenesis is required for radiation-induced apoptosis in the germ line of C. elegans. Science 322: $110-115$.

Derry JM, Gormally E, Means GD, Zhao W, Meindl A, Kelley RI, Boyd Y, Herman GE. 1999. Mutations in a $\Delta 8-\Delta 7$ sterol isomerase in the tattered mouse and $\mathrm{X}$-linked dominant chondrodysplasia punctata. Nat Genet 22: 286-290.

Desmond E, Gribaldo S. 2009. Phylogenomics of sterol synthesis: Insights into the origin, evolution, and diversity of a key eukaryotic feature. Genome Biol Evol 1: 364-381.
Dickson RC. 2008. Thematic review series: sphingolipids. New insights into sphingolipid metabolism and function in budding yeast. J Lipid Res 49: 909-921.

Dickson RC, Lester RL. 1999. Metabolism and selected functions of sphingolipids in the yeast Saccharomyces cerevisiae. Biochim Biophys Acta 1438: 305-321.

Dickson RC, Sumanasekera C, Lester RL. 2006. Functions and metabolism of sphingolipids in Saccharomyces cerevisiae. Prog Lipid Res 45: 447-465.

Dunn TM, Gable K, Monaghan E, Bacikova D. 2000. Selection of yeast mutants in sphingolipid metabolism. Methods Enzymol 312: 317-330.

Ejsing CS, Sampaio JL, Surendranath V, Duchoslav E, Ekroos K, Klemm RW, Simons K, Shevchenko A. 2009. Global analysis of the yeast lipidome by quantitative shotgun mass spectrometry. Proc Natl Acad Sci 106: 2136-2141.

Emter R, Heese-Peck A, Kralli A. 2002. ERG6 and PDR5 regulate small lipophilic drug accumulation in yeast cells via distinct mechanisms. FEBS Lett 521: 57-61.

Fei W, Alfaro G, Muthusamy BP, Klaassen Z, Graham TR, Yang H, Beh CT. 2008. Genome-wide analysis of sterollipid storage and trafficking in Saccharomyces cerevisiae. Eukaryot Cell 7: 401-414.

Fitzky BU, Glossmann H, Utermann G, Moebius FF. 1999. Molecular genetics of the Smith-Lemli-Opitz syndrome and postsqualene sterol metabolism. Curr Opin Lipidol 10: $123-131$.

Friant S, Zanolari B, Riezman H. 2000. Increased protein kinase or decreased PP2A activity bypasses sphingoid base requirement in endocytosis. EMBO J 19: $2834-$ 2844.

Friant S, Lombardi R, Schmelzle T, Hall MN, Riezman H. 2001. Sphingoid base signaling via $\mathrm{Pkh}$ kinases is required for endocytosis in yeast. EMBO J 20: 67836792.

Funato K, Riezman H. 2001. Vesicular and nonvesicular transport of ceramide from ER to the Golgi apparatus in yeast. J Cell Biol 155: 949-959.

Futerman AH, Riezman H. 2005. The ins and outs of sphingolipid synthesis. Trends Cell Biol 15: 312-318.

Fyrst H, Saba JD. 2010. An update on sphingosine-1phosphate and other sphingolipid mediators. Nat Chem Biol 6: 489-497.

Gaber RF, Copple DM, Kennedy BK, Vidal M, Bard M. 1989. The yeast gene ERG6 is required for normal membrane function but is not essential for biosynthesis of the cell-cycle-sparking sterol. Mol Cell Biol 9: 34473456.

Gaigg B, Toulmay A, Schneiter R. 2006. Very long-chain fatty acid-containing lipids rather than sphingolipids per se are required for raft association and stable surface transport of newly synthesized plasma membrane ATPase in yeast. J Biol Chem 281: 34135-34145.

Gaigg B, Timischl B, Corbino L, Schneiter R. 2005. Synthesis of sphingolipids with very long chain fatty acids but not ergosterol is required for routing of newly synthesized plasma membrane ATPase to the cell surface of yeast. $J$ Biol Chem 280: 22515-22522. 
J.T. Hannich et al.

Galea AM, Brown AJ. 2009. Special relationship between sterols and oxygen: Were sterols an adaptation to aerobic life? Free Radic Biol Med 47: 880-889.

Garrenton LS, Young SL, Thorner J. 2006. Function of the MAPK scaffold protein, Ste5, requires a cryptic $\mathrm{PH}$ domain. Genes Dev 20: 1946-1958.

Gaylor JL. 2002. Membrane-bound enzymes of cholesterol synthesis from lanosterol. Biochem Biophys Res Comm 292: $1139-1146$.

Geiger O, Gonzalez-Silva N, Lopez-Lara IM, Sohlenkamp C. 2010. Amino acid-containing membrane lipids in bacteria. Prog Lipid Res 49: 46-60.

Guan XL, Souza CM, Pichler H, Dewhurst G, Schaad O, Kajiwara K, Wakabayashi H, Ivanova T, Castillon GA, Piccolis M, et al. 2009. Functional interactions between sphingolipids and sterols in biological membranes regulating cell physiology. Mol Biol Cell 20: 2083-2095.

Haines TH. 2001. Do sterols reduce proton and sodium leaks through lipid bilayers?. Prog Lipid Res 40: 299-324.

Hait NC, Allegood J, Maceyka M, Strub GM, Harikumar KB, Singh SK, Luo C, Marmorstein R, Kordula T, Milstien S, et al. 2009. Regulation of histone acetylation in the nucleus by sphingosine-1-phosphate. Science 325: $1254-1257$.

Han X, Jiang X. 2009. A review of lipidomic technologies applicable to sphingolipidomics and their relevant applications. Eur J Lipid Sci Technol 111: 39-52.

Hanada K, Kumagai K, Yasuda S, Miura Y, Kawano M, Fukasawa M, Nishijima M. 2003. Molecular machinery for non-vesicular trafficking of ceramide. Nature 426: 803-809.

Hannun YA, Obeid LM. 2009. Principles of bioactive lipid signalling: lessons from sphingolipids. Nat Rev Mol Cell Biol 9: 139-150.

Hannich JT, Entchev EV, Mende F, Boytchev H, Martin R, Zagoriy V, Theumer G, Riezman I, Riezman H, Knolker HJ, et al. 2009. Methylation of the sterol nucleus by STRM-1 regulates dauer larva formation in Caenorhabditis elegans. Dev Cell 16: 833-843.

Heese-Peck A, Pichler H, Zanolari B, Watanabe R, Daum G, Riezman H. 2002. Multiple functions of sterols in yeast endocytosis. Mol Biol Cell 13: 2664-2680.

Ho CH, Magtanong L, Barker SL, Gresham D, Nishimura S, Natarajan P, Koh JL, Porter J, Gray CA, Andersen RJ, et al. 2009. A molecular barcoded yeast ORF library enables mode-of-action analysis of bioactive compounds. Nat Biotechnol 27: 369-377.

Horvath A, Sutterlin C, Manning-Krieg U, Movva NR, Riezman H. 1994. Ceramide synthesis enhances transport of GPI-anchored proteins to the Golgi apparatus in yeast. EMBO J 13: 3687-3695.

Imgrund S, Hartmann D, Farwanah $\mathrm{H}$, Eckhardt $\mathrm{M}$, Sandhoff R, Degen J, Gieselmann V, Sandhoff K, Willecke K. 2009. Adult ceramide synthase 2 (CERS2)-deficient mice exhibit myelin sheath defects, cerebellar degeneration, and hepatocarcinomas. J Biol Chem 284: 3354933560 .

Jiang X, Cheng H, Yang K, Gross RW, Han X. 2007. Alkaline methanolysis of lipid extracts extends shotgun lipidomics analyses to the low-abundance regime of cellular sphingolipids. Anal Biochem 371: 135-145.

Jin H, McCaffery JM, Grote E. 2008. Ergosterol promotes pheromone signaling and plasma membrane fusion in mating yeast. J Cell Biol 180: 813-826.

Kajiwara K, Watanabe R, Pichler H, Ihara K, Murakami S, Riezman H, Funato K. 2008. Yeast ARV1 is required for efficient delivery of an early GPI intermediate to the first mannosyltransferase during GPI assembly and controls lipid flow from the endoplasmic reticulum. Mol Biol Cell 19: 2069-2082.

Klemm RW, Ejsing CS, Surma MA, Kaiser HJ, Gerl MJ, Sampaio JL, de Robillard Q, Ferguson C, Proszynski TJ, Shevchenko A, et al. 2009. Segregation of sphingolipids and sterols during formation of secretory vesicles at the trans-Golgi network. J Cell Biol 185: 601-612.

Kurzchalia TV, Ward S. 2003. Why do worms need cholesterol?. Nat Cell Biol 5: 684-688.

Lamb DC, Jackson CJ, Warrilow AG, Manning NJ, Kelly DE, Kelly SL. 2007. Lanosterol biosynthesis in the prokaryote Methylococcus capsulatus: Insight into the evolution of sterol biosynthesis. Mol Biol Evol 24: 1714-1721.

Lee MCS, Hamamoto S, Schekman R. 2002. Ceramide biosynthesis is required for the formation of the oligomeric $\mathrm{H}+$-ATPase Pmalp in the yeast endoplasmic reticulum. J Biol Chem 277: 22395-22401.

Lingwood D, Simons K. 2010. Lipid rafts as a membraneorganizing principle. Science 327: 46-50.

Lisman Q, Pomorski T, Vogelzangs C, Urli-Stam D, de Cocq van Delwijnen W, Holthuis JC. 2004. Protein sorting in the late Golgi of Saccharomyces cerevisiae does not require mannosylated sphingolipids. J Biol Chem 279: 1020 1029.

Liu K, Zhang X, Lester RL, Dickson RC. 2005. The sphingoid long chain base phytosphingosine activates AGC-type protein kinases in Saccharomyces cerevisiae including Ypk1, Ypk2, and Sch9. J Biol Chem 280: 22679-22687.

Marza E, Simonsen KT, Faergeman NJ, Lesa GM. 2009. Expression of ceramide glucosyltransferases, which are essential for glycosphingolipid synthesis, is only required in a small subset of C. elegans cells. J Cell Sci 122: $822-833$.

Meier KD, Deloche O, Kajiwara K, Funato K, Riezman H. 2006. Sphingoid base is required for translation initiation during heat stress in Saccharomyces cerevisiae. Mol Biol Cell 17: 1164-1175.

Menuz V, Howell KS, Gentina S, Epstein S, Riezman I, Fornallaz-Mulhauser M, Hengartner MO, Gomez M, Riezman H, Martinou JC. 2009. Protection of C. elegans from anoxia by HYL-2 ceramide synthase. Science 324: 381-384.

Merrill AH Jr, Stokes TH, Momin A, Park H, Portz BJ, Kelly S, Wang E, Sullards MC, Wang MD. 2009. Sphingolipidomics: A valuable tool for understanding the roles of sphingolipids in biology and disease. J Lipid Res 50 Suppl: S97-102.

Mesmin B, Maxfield FR. 2009. Intracellular sterol dynamics. Biochim Biophys Acta 1791: 636-645.

Munn AL, Riezman H. 1994. Endocytosis is required for the growth of vacuolar $\mathrm{H}(+)$-ATPase-defective yeast 
identification of six new END genes. J Cell Biol 127: 373-386.

Munn AL, Heese-Peck A, Stevenson BJ, Pichler H, Riezman H. 1999. Specific sterols required for the internalization step of endocytosis in yeast. Mol Biol Cell 10: 3943-3957.

Nakase M, Tani M, Morita T, Kitamoto HK, Kashiwazaki J, Nakamura T, Hosomi A, Tanaka N, Takegawa K. 2010. Mannosylinositol phosphorylceramide is a major sphingolipid component and is required for proper localization of plasma-membrane proteins in Schizosaccharomyces pombe. J Cell Sci 123: 1578-1587.

Nishimura S, Arita Y, Honda M, Iwamoto K, Matsuyama A, Shirai A, Kawasaki H, Kakeya H, Kobayashi T, Matsunaga S, et al. 2010. Marine antifungal theonellamides target $3 \beta$-hydroxysterol to activate Rhol signaling. Nat Chem Biol 6: 519-526.

Ohyama K, Suzuki M, Kikuchi J, Saito K, Muranaka T. 2009. Dual biosynthetic pathways to phytosterol via cycloartenol and lanosterol in Arabidopsis. Proc Natl Acad Sci 106: $725-730$.

Osborne TF, Espenshade PJ. 2009. Evolutionary conservation and adaptation in the mechanism that regulates SREBP action: What a long, strange tRIP it's been. Genes Dev 23: 2578-2591.

Pata MO, Hannun YA, Ng CK. 2010. Plant sphingolipids: decoding the enigma of the Sphinx. New Phytol 185: 611-630.

Pearson A, Budin M, Brocks JJ. 2003. Phylogenetic and biochemical evidence for sterol synthesis in the bacterium Gemmata obscuriglobus. Proc Natl Acad Sci 100: $15352-15357$.

Penno A, Reilly MM, Houlden H, Laura M, Rentsch K, Niederkofler V, Stoeckli ET, Nicholson G, Eichler F, Brown RH Jr, et al. 2010. Hereditary sensory neuropathy type 1 is caused by the accumulation of two neurotoxic sphingolipids. J Biol Chem 285: 11178-11187.

Pewzner-Jung Y, Brenner O, Braun S, Laviad EL, Ben-Dor S, Feldmesser E, Horn-Saban S, Amann-Zalcenstein D, Raanan C, Berkutzki T, et al. 2010a. A critical role for ceramide synthase 2 in liver homeostasis: II. Insights into molecular changes leading to hepatopathy. J Biol Chem 285: 10911-10923.

Pewzner-Jung Y, Park H, Laviad EL, Silva LC, Lahiri S, Stiban J, Erez-Roman R, Brugger B, Sachsenheimer T, Wieland F, et al. 2010b. A critical role for ceramide synthase 2 in liver homeostasis: I. Alterations in lipid metabolic pathways. J Biol Chem 285: 10902-10910.

Pryciak PM, Huntress FA. 1998. Membrane recruitment of the kinase cascade scaffold protein Ste5 by the Gßy complex underlies activation of the yeast pheromone response pathway. Genes Dev 12: 2684-2697.

Radhakrishnan A, Goldstein JL, McDonald JG, Brown MS. 2008. Switch-like control of SREBP-2 transport triggered by small changes in ER cholesterol: A delicate balance. Cell Metab 8: 512-521.

Rao RP, Acharya JK. 2008. Sphingolipids and membrane biology as determined from genetic models. Prostaglandins Other Lipid Mediat 85: 1-16.

Reggiori F, Canivenc-Gansel E, Conzelmann A. 1997. Lipid remodeling leads to the introduction and exchange of defined ceramides on GPI proteins in the
ER and Golgi of Saccharomyces cerevisiae. EMBO J 16: 3506-3518.

Sancak Y, Bar-Peled L, Zoncu R, Markhard AL, Nada S, Sabatini DM. 2010. Ragulator-Rag complex targets mTORC1 to the lysosomal surface and is necessary for its activation by amino acids. Cell 141: 290-303.

Santarella-Mellwig R, Franke J, Jaedicke A, Gorjanacz M, Bauer U, Budd A, Mattaj IW, Devos DP. 2010. The compartmentalized bacteria of the planctomycetesverrucomicrobia-chlamydiae superphylum have membrane coat-like proteins. PLoS Biol 8: e1000281.

Schmidt A, Beck T, Koller A, Kunz J, Hall MN. 1998. The TOR nutrient signalling pathway phosphorylates NPR1 and inhibits turnover of the tryptophan permease. EMBO J 17: 6924-6931.

Schonbachler M, Horvath A, Fassler J, Riezman H. 1995. The yeast spt14 gene is homologous to the human PIG-A gene and is required for GPI anchor synthesis. EMBO J 14: 1637-1645.

Schwudke D, Schuhmann K, Herzog R, Bornstein SR, Shevchenko A. 2011. Shotgun lipidomics on high resolution mass spectrometers. Cold Spring Harb Perspect Biol doi: $10.1101 /$ cshperspect.a004614.

Silberkang M, Havel CM, Friend DS, McCarthy BJ, Watson JA. 1983. Isoprene synthesis in isolated embryonic Drosophila cells. I. Sterol-deficient eukaryotic cells. J Biol Chem 258: 8503-8511.

Silve S, Dupuy PH, Labit-Lebouteiller C, Kaghad M, Chalon P, Rahier A, Taton M, Lupker J, Shire D, Loison G. 1996. Emopamil-binding protein, a mammalian protein that binds a series of structurally diverse neuroprotective agents, exhibits $\Delta 8-\Delta 7$ sterol isomerase activity in yeast. J Biol Chem 271: 22434-22440.

Skrzypek MS, Nagiec MM, Lester RL, Dickson RC. 1998. Inhibition of amino acid transport by sphingoid long chain bases in Saccharomyces cerevisiae. J Biol Chem 273: $2829-2834$.

Sperling P, Heinz E. 2003. Plant sphingolipids: Structural diversity, biosynthesis, first genes and functions. Biochim Biophys Acta 1632: 1-15.

Sprong H, Degroote S, Claessens T, van Drunen J, Oorschot V, Westerink BH, Hirabayashi Y, Klumperman J, van der Sluijs P, van Meer G. 2001. Glycosphingolipids are required for sorting melanosomal proteins in the Golgi complex. J Cell Biol 155: 369-380.

Sturgill TW, Cohen A, Diefenbacher M, Trautwein M, Martin DE, Hall MN. 2008. TOR1 and TOR2 have distinct locations in live cells. Eukaryot Cell 7: 1819-1830.

Sullards MC, Allegood JC, Kelly S, Wang E, Haynes CA, Park H, Chen Y, Merrill AH Jr. 2007. Structure-specific, quantitative methods for analysis of sphingolipids by liquid chromatography-tandem mass spectrometry: "Inside-out" sphingolipidomics. Methods Enzymol 432: 83-115.

Summons RE, Powell TG, Boreham CJ. 1988. Petroleum geology and geochemistry of the Middle Proterozoic McArthur Basin, Northern Australia: III. Composition of extractable hydrocarbons. Geochimica et Cosmochimica Acta 52: 1747-1763.

Sun Y, Taniguchi R, Tanoue D, Yamaji T, Takematsu H, Mori K, Fujita T, Kawasaki T, Kozutsumi Y. 2000. Sli2 (Ypk1), a homologue of mammalian protein kinase 
J.T. Hannich et al.

SGK, is a downstream kinase in the sphingolipidmediated signaling pathway of yeast. Mol Cell Biol 20: 4411-4419.

Ternes P, Sperling P, Albrecht S, Franke S, Cregg JM, Warnecke D, Heinz E. 2006. Identification of fungal sphingolipid C9-methyltransferases by phylogenetic profiling. J Biol Chem 281: 5582-5592.

Todd BL, Stewart EV, Burg JS, Hughes AL, Espenshade PJ. 2006. Sterol regulatory element binding protein is a principal regulator of anaerobic gene expression in fission yeast. Mol Cell Biol 26: 2817-2831.

Umebayashi K, Nakano A. 2003. Ergosterol is required for targeting of tryptophan permease to the yeast plasma membrane. J Cell Biol 161: 1117-1131.

Vacaru AM, Tafesse FG, Ternes P, Kondylis V, Hermansson M, Brouwers JF, Somerharju P, Rabouille C, Holthuis JC. 2009. Sphingomyelin synthase-related protein SMSr controls ceramide homeostasis in the ER. J Cell Biol 185: 1013-1027.

Vaena de Avalos S, Okamoto Y, Hannun YA. 2004. Activation and localization of inositol phosphosphingolipid phospholipase $\mathrm{C}$, Isclp, to the mitochondria during growth of Saccharomyces cerevisiae. J Biol Chem 279: 11537-11545.

Vinci G, Xia X, Veitia RA. 2008. Preservation of genes involved in sterol metabolism in cholesterol auxotrophs: Facts and hypotheses. PLoS One 3: e2883.
Volkman JK. 2003. Sterols in microorganisms. Appl Microbiol Biotechnol 60: 495-506.

Watanabe R, Funato K, Venkataraman K, Futerman AH, Riezman H. 2002. Sphingolipids are required for the stable membrane association of glycosylphosphatidylinositol-anchored proteins in yeast. J Biol Chem 277: 49538-49544.

Weete JD, Abril M, Blackwell M. 2010. Phylogenetic distribution of fungal sterols. PLoS One 5: e10899.

Xu J, Dang Y, Ren YR, Liu JO. 2010. Cholesterol trafficking is required for mTOR activation in endothelial cells. Proc Natl Acad Sci 107: 4764-4769.

Yamashita M, Matsuda M, Mori T. 1999. In situ detection of prolactin receptor mRNA and apoptotic cell death in mouse uterine tissues with adenomyosis. In Vivo 13: 57-60.

Yard BA, Carter LG, Johnson KA, Overton IM, Dorward M, Liu H, McMahon SA, Oke M, Puech D, Barton GJ, et al. 2007. The structure of serine palmitoyltransferase; gateway to sphingolipid biosynthesis. J Mol Biol 370: 870-886.

Ye J, DeBose-Boyd RA. 2011. Regulation of cholesterol and fatty acid synthesis. Cold Spring Harb Perspect Biol doi:10.1101/cshperspect.a004754.

Zanolari B, Friant S, Funato K, Sutterlin C, Stevenson BJ, Riezman H. 2000. Sphingoid base synthesis requirement for endocytosis in Saccharomyces cerevisiae. EMBO J 19: 2824-2833. 


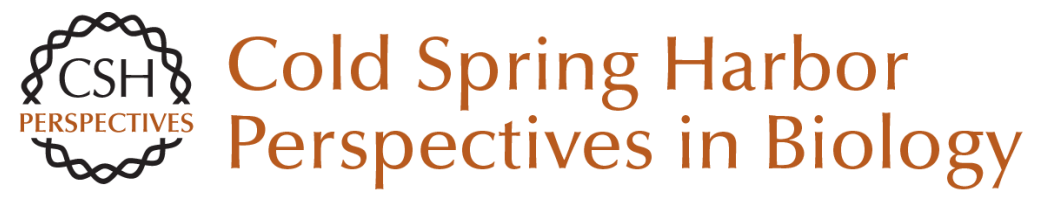

\section{Distribution and Functions of Sterols and Sphingolipids}

J. Thomas Hannich, Kyohei Umebayashi and Howard Riezman

Cold Spring Harb Perspect Biol 2011; doi: 10.1101/cshperspect.a004762 originally published online March 30, 2011

\section{Subject Collection The Biology of Lipids}

Role of Lipids in Virus Replication Maier Lorizate and Hans-Georg Kräusslich

Model Answers to Lipid Membrane Questions Ole G. Mouritsen

\section{Glycosphingolipid Functions} Clifford A. Lingwood

Regulation of Cholesterol and Fatty Acid Synthesis

Jin Ye and Russell A. DeBose-Boyd

\section{Lipid-Mediated Endocytosis}

Helge Ewers and Ari Helenius

\section{Fluorescence Techniques to Study Lipid}

Dynamics

Erdinc Sezgin and Petra Schwille

Lysosomal Lipid Storage Diseases

Heike Schulze and Konrad Sandhoff

\section{Distribution and Functions of Sterols and} Sphingolipids

J. Thomas Hannich, Kyohei Umebayashi and Howard Riezman
Membrane Organization and Lipid Rafts Kai Simons and Julio L. Sampaio

Shotgun Lipidomics on High Resolution Mass

Spectrometers

Dominik Schwudke, Kai Schuhmann, Ronny

Herzog, et al.

Glycosphingolipid Functions Clifford A. Lingwood

Phosphoinositides in Cell Architecture Annette Shewan, Dennis J. Eastburn and Keith Mostov

Synthesis and Biosynthetic Trafficking of Membrane Lipids Tomas Blom, Pentti Somerharju and Elina Ikonen

Lipid Polymorphisms and Membrane Shape Vadim A. Frolov, Anna V. Shnyrova and Joshua Zimmerberg

Specificity of Intramembrane Protein-Lipid Interactions

Francesc-Xabier Contreras, Andreas Max Ernst, Felix Wieland, et al.

Dynamic Transbilayer Lipid Asymmetry Gerrit van Meer

For additional articles in this collection, see http://cshperspectives.cshlp.org/cgi/collection/

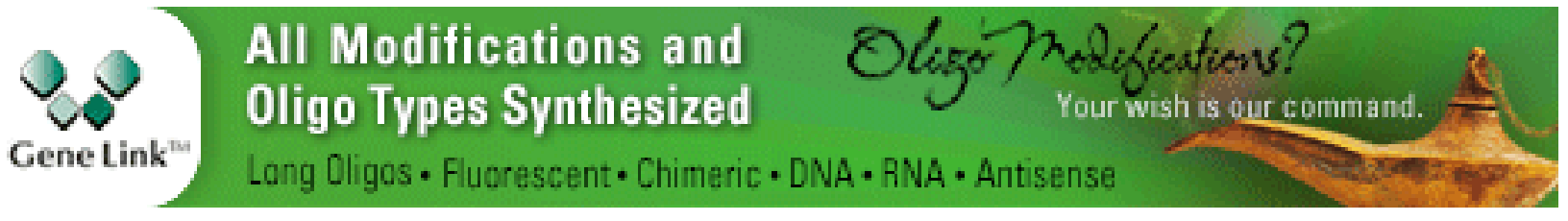

Copyright @ 2011 Cold Spring Harbor Laboratory Press; all rights reserved 